\title{
Comprehensive evaluation of sugar beet genotypes for yield and relative traits by multivariate analysis
}

\author{
Mehareb E.M., * H.M.Y. EL-Bakary and Fouz. F.M. Abo elenen
}

Sugar Crops Research Institute, Agriculture Research Center, Egypt

\begin{abstract}
Among few methods suggested for evaluation of the genotype-environment interactions (GE interaction), the AMMI method (Additive main Effect and Multiplicative Interaction) is the most instructive model. The objective of this experiment was to estimate the $\mathrm{G} \times \mathrm{E}$ interaction in sugar beet varieties of stability and adaptability through different environments using the AMMI model. As well as cluster analysis was automated to identify the interrelationships among the tested varieties, also Principal component analysis (PCA) was used to define the relationship between the studied traits. Twenty genotypes of sugar beet were evaluated at two locations (El- Dakahlia and El- Fayoum stations) in Egypt in two seasons (2018/2019 and 2019/2020). A randomized complete block design with three replications was used in each environment. Results showed that the AMMI analysis of variance was highly significant differences for the environment, variety, and their interactions. Based on AMMI model, Glorius, Florima, Capel, Belatos, Classic and Toro genotypes in EN3 (Dakahlia 2019/2020), have the highest sugar yield, respectively. Results of cluster analysis demonstrated an extensive genetic diversity among the tested varieties, also the $1^{\text {st }}$ sub cluster, (cluster I) was recorded high values of root weight, length, diameter and total weight. It was found that cluster II (Farida, Toro, Capel, Florima, Betamax, Glorius ) recorded the highest root and sugar yield, which led to increase of $106.66 \%$ and $112.91 \%$ higher than that compared with cluster V (Lilly, Heba, Mirador). According to PCA results, PCA1 accounted for $69.5 \%$ of the total phenotypic variation expressed and PCA2 accounted for $27.03 \%$ of the variation. Characters accounting for the most of difference expressed in the PCA1 were root weight and root diameter. While the main traits in PCA 2 were root weight and root length.
\end{abstract}

Keywords: AMMI; Principal component analysis; Sugar beet genotypes

\section{Introduction}

Sugar beet (Beta vulgaris L.) became the first industrial sugar crop in Egypt. Sugar beet is cultivated in an area 608627 feddan (about 255725.6 hectares) (Annual Report of Egyptian Sugar Crops Council, December 2019) Consequently, evaluating of sugar beet

\footnotetext{
*Corresponding author: Eid M. Mehareb

Email: elmoharb@yahoo.com

Received: 20. January, 2021;

Accepted: February 20, 2021;
}

Published: March 13, 2021. genotypes under Egyptian conditions to select the best ones characterized with high yield and quality characteristics to improve their productivity as an urgent demand to meet sugar consumption or at least to reduce the Egyptian sugar gap. In breeding programs, genotypes should be evaluated in several environmental conditions, in other words, in 
dissimilar years and locations, so that the information obtained from the estimation of the compatibility and stability of genotypes performance is a reliable criterion in recommending genotypes and provides the efficiency of selection and realization of cultivars (Ebdon and Gauch, 2002;).

The main aim of growing almost each agricultural crop is achieving great and stable yields, regarding maximum utilization of environmental conditions. Into the applied cultivation practices, important part of this process is the selection of the most suitable variety. Beside hereditary and environmental factors, productivity of varieties is as well influenced by their interaction (Abo elenen $e t$ al. 2019).

Numerous trials have been done in evaluating the stability of different sugar beet genotypes in dissimilar regions through using the methods of parametric univariate (Keshavarz et al. 2001), regression analysis is certainly the most common method for stability analysis caused by its simplicity and the fact that its information on adaptive response is easily applicable to locations. Moreover, using multivariate analysis and AMMI model (Ranji et al. 2005).

The method AMMI is one of the best capable methods of stability analysis in regional experiments (Crossa 1990). In this method the existence of the first two significant components is the best state for the evaluation of interaction of variety and environment (Akura et al. 2005).

Agglomerative Cluster Analysis (AHC) and Principal Component Analysis (PCA) are widely used tools in many experimental procedures for better understanding of data as PCA helps to reduce the variables and demonstrates the relationship among these variables [Mundaragi et al. 2017]. Additional, numerous studies show that multivariate statistical analysis; viz. cluster analysis (CA) and PCA are more effective in estimating genetic diversity among genotypes [Baloch 2017]. The basic objective of using a cluster method in the analysis of data from plant breeding trials is to group the genotypes into numerous homogeneous groups such that those genotypes inside a group have a similar response pattern through the environments. Cluster analysis can identify variances among varieties for the breeder via classification of varieties (Sabaghnia et al., 2012). Cluster analysis is an effective tool targeted to quantify the degree of genetic divergence among studied varieties based on their performance and their contributing traits. The cluster analysis was used as an efficient procedure to emerge the structural relationships among tested germplasm and offers a hierarchical classification of them (Abo elenen et al. 2019). Some indicators of different varieties of sugar beet have been used to evaluate the traits of sugar beet and distinguish various cultivars $(\mathrm{Hu}$ et al 2016).Furthermore, analysis and comprehensive evaluations have been performed on the amino acid components in the roots of twenty genotypes of sugar beet by using the PCA technique $\mathrm{Hu}$ et al. 2016.The objective of this study was to evaluate variances between randomly twenty sugar beet genotypes from the collection at Sugar Crops Research Institute, ARC, Egypt and to estimate the $\mathrm{G} \times \mathrm{E}$ interaction in sugar beet varieties of stability and adaptability through different environments using the AMMI model. As well as cluster analysis was automated to identify the interrelationships among the tested varieties. 


\section{MATERIALS AND METHODS}

Twenty sugar beet varieties (presented in Table 1) were evaluated in an experiment under two locations in sugar beet growing areas El-Dakahlya research station (latitude of $31.5 \mathrm{~N}$ and longitude of $30.32 \mathrm{E}$ and elevation of $15 \mathrm{~m}$ above sea level) and El-Fayoum research station (latitude $29.30 \quad 0 \quad \mathrm{~N}$ and longitude $30.840 \mathrm{E}$ and elevation of $13 \mathrm{~m}$ beyond sea level), Egypt. A randomized complete block design with three replications in 2018/19 and 2019/20 seasons was alone to evaluate the choice sugar beet genotypes to $G$ $\mathrm{x} E$ interaction, stability and adaptability throughout the different environments by using AMMI model.
Sowing was performed in the $1^{\text {st }}$ week of October in the first and second season. Carried the experiment out in randomized complete block design with three replications. Where locations were allocated in the main plots while sugar beet varieties were randomly distributed in the sub plots. Sub plot area was $20 \mathrm{~m} 2$ including 4 ridges, $10 \mathrm{~m}$ long and 50 $\mathrm{cm}$ width with $20-\mathrm{cm}$ hill spacing. Crops were harvested manually after 210 days from sowing. During the growing season frequently agricultural practices for sugar beet were applied according to the recommendation of Sugar Crops Research Institute in Egypt.

Table 1. Name and origin of sugar beet genotypes used in this study

\begin{tabular}{clllll}
\hline No. & $\begin{array}{c}\text { Sugar beet } \\
\text { Varieties }\end{array}$ & Origin & No. & Sugar beet Varieties & Origin \\
\hline 1 & Athos poly & Netherland & 11 & Florima & France \\
2 & Helios poly & Netherland & 12 & Panther & Germany \\
3 & Farida & Germany & 13 & Dema poly & Germany \\
4 & Pleno & Germany & 14 & Oscar poly & Germany \\
5 & Tenor & Germany & 15 & Betamax & France \\
6 & Belatos & France & 16 & Glorius & Germany \\
7 & Toro & Germany & 17 & Hercule & Germany \\
8 & Gazelle & Germany & 18 & Lilly & Germany \\
9 & Capel & France & 19 & Heba & Germany \\
10 & Classic & Germany & 20 & Mirador & Germany \\
\hline
\end{tabular}

A sample of 10- plants of sugar beet randomly were taken at age of 210 days from each plot in order to determine the following traits : root length $(\mathrm{cm})$, root weight/plant $(\mathrm{Kg})$, root diameter $(\mathrm{cm})$ Root fresh weight (g/plant) Extracted sugar \% $=(\mathrm{Pol} \%-0.29)-0.343 *(\mathrm{~K}$ $+\mathrm{Na})-\alpha$ - amino $\mathrm{N} *(0.0939)$ and sucrose $\%$ percentage (Pol\%) was estimated in fresh samples of sugar beet roots, using Saccharometer according to the method described in A.O.A.C. (2005).,. Juice quality index (QI \%) was calculated according to Cooke and Scott (1993) using the following equation: Quality index\% = extracted sugar $\%$ (\%) / POL $\times 100$, root yield (ton/fed), tops yield (ton/fed) Sugar yield (t/fed) was calculated according to the following equation: sugar equation: sugar yield $(\mathrm{t} / \mathrm{fed})=$ root yield (t/fed) $x$ extracted sugar\%. Chemical and mechanical properties of the experimental soil are presented in Table (2). Meteorological data 
recorded at the experimental sites are shown in Table (3).

The recorded data were statistically analyzed according to Keshavarz et al. 2001). Least significant difference test at 5\% level of probability was used to compare means.

Statistical analysis AMMI Biplot analysis
To analyze of the interaction of variety $x$ environment, the AMMI model equation was used according to Gauch and Zobel, (1996). To determine genotypes stability, the first and second main components were used, to relate the different genotypes to the dissimilar environments the biplot diagrams were utilized as described by Gabriel, (1971).

Table 2. Chemical and physical properties of a representative soil of the two locations ( 2018/2019 and 2019/2020 seasons).

\begin{tabular}{|c|c|c|c|c|}
\hline \multirow{2}{*}{$\begin{array}{c}\text { Location } \\
\text { Seasons }\end{array}$} & \multicolumn{2}{|c|}{ EL-Dakahlia } & \multicolumn{2}{|c|}{ EL-Fayoum } \\
\hline & 2018/2019 & $2019 / 2020$ & 2018/2019 & $2019 / 2020$ \\
\hline Soil texture & \multicolumn{2}{|c|}{$\begin{array}{l}\text { Sandy Loam } \\
\end{array}$} & \multicolumn{2}{|c|}{ Clay Loamy } \\
\hline Sand\% & 88.95 & 92.62 & 24.10 & 25.50 \\
\hline Silt\% & 3.55 & 2.30 & 36.60 & 37.60 \\
\hline Clay\% & 7.50 & 5.08 & 39.30 & 36.90 \\
\hline \multicolumn{5}{|c|}{ Cations (meg/L.) } \\
\hline E.C.(dsm) & 2.96 & 3.20 & 3.43 & 3.71 \\
\hline PH (1:2.5) & 8.28 & 8.35 & 8.31 & 8.29 \\
\hline $\mathrm{Ca} * *$ & 0.32 & 2.07 & 9.80 & 11.30 \\
\hline $\mathrm{Mg}^{++}$ & 6.90 & 6.30 & 5.55 & 5.64 \\
\hline $\mathrm{Na}^{+}$ & 13.50 & 16.80 & 18.30 & 19.70 \\
\hline $\mathrm{K}$ & 3.60 & 3.03 & 0.65 & 0.42 \\
\hline \multicolumn{5}{|c|}{ Anions (meg/L.) } \\
\hline $\mathrm{HCO}_{3}^{-}$ & 3.30 & 3.10 & 2.50 & 2.80 \\
\hline $\mathrm{CL}^{-}$ & 12.20 & 11.80 & 26.10 & 29.16 \\
\hline $\mathrm{SO}^{-}$ & 8.82 & 13.30 & 5.70 & 5.10 \\
\hline O.M. $(\%)$ & 0.08 & 0.06 & 0.02 & 0.04 \\
\hline Available $\mathrm{N} \mathrm{mg} / \mathrm{kg}$ & 29.50 & 30.10 & 52.30 & 54.60 \\
\hline Available P mg/kg & 7.20 & 5.30 & 5.17 & 5.42 \\
\hline Available $\mathrm{K} \mathrm{mg} / \mathrm{kg}$ & 95.00 & 99.60 & 142.00 & 148.00 \\
\hline $\begin{array}{l}\text { Stability analyses } \\
\text { Stability analysis of the } \\
\text { varieties was carried out } \mathrm{f} \\
\text { and four field experimer } \\
\text { different environments ( } \mathrm{T} \\
\text { were adopted for estimatir } \\
\text { AMMI biplot method of s } \\
\text { the GeneStat-18 software } 1 \\
\text { Cluster analysis } \\
\text { Hierarchical cluster analys }\end{array}$ & $\begin{array}{l}\text { sugar beet } \\
\text { under study } \\
\text { senting the } \\
\text { Approaches } \\
\text { ty using the } \\
\text { nalysis with }\end{array}$ & \multicolumn{3}{|c|}{$\begin{array}{l}\text { the standardized data using a measure of } \\
\text { Euclidean distance and Ward minimum } \\
\text { variance method as outlined by Ward (1963). } \\
\text { Principal Component Analysis (PCA) } \\
\text { PCA method described by Harman (1976) was } \\
\text { followed in the extraction of the components. } \\
\text { PCA was performed by Minitab } 14 \text { software } \\
\text { and the values of the first five components } \\
\text { were selected and analyzed using SPSS and } \\
\text { the related clusters were plotted based on the } \\
\text { main components. }\end{array}$} \\
\hline
\end{tabular}


Mehareb et al., SVU-International Journal of Agricultural Sciences, 3 (1): 96-111, 2021

Table 3. Monthly average of the EL-Fayoum and EL- Dakahlia Agricultural Research Stations (average of 2018/2019 and 2019/2020 seasons).

\begin{tabular}{|c|c|c|c|c|c|c|}
\hline \multirow{2}{*}{$\begin{array}{l}\text { Location } \\
\text { Month }\end{array}$} & \multicolumn{3}{|c|}{ EL-Fayoum. } & \multicolumn{3}{|c|}{ EL- Dakahlia } \\
\hline & Max & Min & Aver & Max & Min & Aver \\
\hline \multicolumn{7}{|c|}{ 2018-2019 } \\
\hline Oct. & 29.57 & 15.48 & 22.52 & 23.35 & 16.94 & 20.14 \\
\hline Nov. & 23.95 & 10.29 & 17.12 & 21.50 & 15.10 & 18.30 \\
\hline Dec. & 20.68 & 8.26 & 14.47 & 18.83 & 12.47 & 15.65 \\
\hline Jan. & 18.46 & 4.75 & 11.6 & 17.73 & 10.1 & 13.92 \\
\hline Feb. & 24.29 & 9.94 & 17.12 & 18.31 & 12.2 & 15.26 \\
\hline Mar. & 23.9 & 15.97 & 19.93 & 19.45 & 13.55 & 16.5 \\
\hline Apr. & 29.21 & 18.57 & 23.89 & 21.34 & 15.66 & 18.5 \\
\hline \multicolumn{7}{|c|}{ 2019-2020 } \\
\hline Oct. & 30.47 & 21.7 & 26.08 & 27.77 & 22.57 & 25.17 \\
\hline Nov. & 27.3 & 17.83 & 22.57 & 25.2 & 20.09 & 22.64 \\
\hline Dec. & 30.16 & 21.14 & 25.65 & 19.77 & 14.07 & 16.92 \\
\hline Jan. & 17.03 & 9.63 & 13.33 & 17.17 & 10.9 & 14.03 \\
\hline Feb. & 19.56 & 11.44 & 15.5 & 18.53 & 11.94 & 15.23 \\
\hline Mar. & 23.16 & 13.7 & 18.43 & 20.57 & 14.07 & 17.32 \\
\hline Apr. & 26.55 & 15.86 & 21.21 & 22.61 & 16.28 & 19.45 \\
\hline
\end{tabular}

Table 4. Locations, seasons and Average Air temperature $\left({ }^{\circ} \mathrm{C}\right)$ (mean of 7 months) of the four tested environments (E1 to E4)

\begin{tabular}{cccccc}
\hline Environment & Location & season & \multicolumn{2}{c}{$\begin{array}{c}\text { Average Air temperature }\left({ }^{\circ} \mathbf{C}\right)(\text { mean of 7 } \\
\text { months })\end{array}$} \\
\cline { 4 - 6 } & & & Max & Min & Average \\
\hline EN1 & El- Dakahlia & $2018-19$ & 20.07 & 13.72 & 16.90 \\
EN2 & El- Fayoum & $2018-19$ & 24.29 & 11.89 & 18.09 \\
EN3 & El- Dakahlia & $2019-20$ & 21.66 & 15.70 & 18.68 \\
EN4 & El- Fayoum & $2019-20$ & 24.89 & 15.90 & 20.40 \\
\hline
\end{tabular}

\section{RESULTS AND DISCUSSION}

\section{AMMI analysis of variance}

In any breeding program, it is essential to screen and recognize phenotypic ally stable genotypes; Development of a stable genotype is one of the main goals of all breeding programs. Phenotypic ally stable genotypes are usefully sought for commercial production of crop plants, which could perform more or less uniformly under dissimilar environmental conditions. Numerous models have been proposed for stability analysis; the most important are AMMI model.

Combined analysis of variance shown highly significant $(\mathrm{P} \leq 0.01)$ variances with reason environments, variety $\times$ environment interaction and IPCAs (Table 5). This result 
exposed that there was a variance yield performance among the sugar beet varieties through studied environments and the presence of strong genotype by environment $(\mathbf{G} \times \mathbf{E})$ interaction. As $\mathbf{G} \times \mathbf{E}$ interaction was significant, additional calculation of genotype stability is possible

Table 5. Additive main effects and multiplicative interaction analysis of variance for root and sugar yield of twenty sugar beet genotypes across four environments

\begin{tabular}{lcccccc}
\hline \multirow{2}{*}{ Source of variance } & \multicolumn{3}{c}{ Root yield } & \multicolumn{3}{c}{ Sugar yield } \\
\cline { 2 - 7 } & d.f. & M.s & Explained (\%) & d.f. & M.s & $\begin{array}{c}\text { Explained } \\
(\%)\end{array}$ \\
\hline Genotypes & 19 & $1.59^{* *}$ & 52.8 & 19 & $0.198^{* *}$ & 31.32 \\
Environments & 3 & $5.837^{* *}$ & 30.59 & 3 & $2.1568^{* *}$ & 53.84 \\
Interactions & 57 & 0.167 & 16.61 & 57 & 0.0313 & 14.83 \\
IPCA 1 & 21 & $0.375^{* *}$ & 82.75 & 21 & $0.0596^{* *}$ & 70.26 \\
IPCA 2 & 19 & 0.051 & 10.09 & 19 & $0.023^{*}$ & 24.52 \\
Residuals & 17 & 0.04 & 7.15 & 17 & 0.0055 & 5.27 \\
\hline
\end{tabular}

The similar twenty sugar beet varieties across four environments were analyzed through AMMI. The results of variance analysis of the characters presented that the main effects of environment and variety were highly significant (Table 5). The existence of highly significant dissimilarity among the varieties was the representation of the variance of genetic potentiality of the genotypes for the studied yield characters; furthermore, the existence of highly significant variance among the evaluated environments represents the significant variety effect in the additive structure of data for the yield characters among the environments. This result is in agreement with (Ranji et al. (2005). The interaction of variety $\times$ environment was highly significant for the studied characters. The genotype contribution to total sum of squares for root and sugar yield were $52.80 \%$ and $31.32 \%$ and the environment contribution were estimated to be $30.59 \%$, and $53.84 \%$, respectively, and for the interaction of variety $\times$ environment, these quantities were $16.61 \%$ and $14.83 \%$, respectively. The existence of high genotype and environment share of the total sum of squares percentages is representative of the variance in the genetic potential of varieties and moreover, the variance in the productivity potential of numerous environments (Aghayee Sarbarzeh et al. 2007 and Ghareeb et al 2014 )that reported the existence of high genotype and environment share of the total sum of squares percentages is representative of the variance in the genetic potential of genotypes and also the variance in the productivity potential of numerous environments.

The interaction of variety $\times$ environment was separated into two main components. The first main component share of the interaction for root and sugar yield, from the variance of interaction of genotype $\times$ environment were $82.75 \%$ and $70.26 \%$ and for the second main component were $10.09 \%$ and $24.52 \%$, respectively (Table 5). The explanation of high percentage of variance of interaction of variety 
$x$ environment with the first two components of the interaction represents this fact that these two components well described the significant interaction of genotype $\times$ environment, due to the multiplicative structure of the data. Farshadfar et al. (2010) indicated that the AMMI technique is appropriate for the stability analysis, paying attention to the fact that it justifies $89.30 \%$ of variety $\times$ environment interaction variations with the first two main components.

\section{AMMI analysis}

The combined analysis of variance and AMMI analysis is presented in Figures $1 \& 2$. It was observed that there were highly significant differences for the environment, variety and their interactions. AMMI biplot analysis for root and sugar yield displayed that the relative variability due to varieties was less than the variability due to most of the environments. Genotypes positioned near the biplot origin were more stable than the genotypes positioned further away which agrees with the report by Ciric et al. (2017). Varieties or environments found on the right-hand side of the midpoint of the axis main effects have higher yields than those on the left-hand side (Ngeve and Bouwkamp 1993).

To additional examine the sugar yield and instability, the figures of the AMMI1 were plotted (Figure 1). In this figure, the vertical line in the middle of the graph represents the total mean sugar yield. The genotypes and locations in right hand of this line have sugar yield above the mean. According to this explanation, Glorius, Florima, Capel, Belatos, Classic and Toro genotypes in EN3 (Dakahlia 2019/2020), were placed in the right side of the perpendicular line in the middle of the biplot, have the highest sugar yield, respectively. According to these characters, Heba had the lowest sugar yield. on the other hand, Betamax followed by Glouris produced the best average root yield (Figure 2).

\section{Relationship between genotypes and environments}

AMMI biplot simultaneously (Figure 1) represents main additive effect and the effect of the first interaction component. It gives vector perspective on connection among genotypes and mega environments for sugar yield, in which environments are associated with biplot origin via lines. AMMI biplot simultaneously represents main additive effect or sugar yield and the effect of the first interaction component. Lower absolute values of IPCA1 score indicate smaller interaction G or E which have small values of IPCA1 and are more stable. According to (Figures 1) they additionally show the relationship among genotypes, which is in agreement with AlNaggar et al. (2018) that reported the biplot helps in the understanding of interrelationship among environments

\section{Cluster Analysis (CA) and Principal components analysis (PCA)}

Clustering analysis (CA) is ordinarily performed to organize samples and variables into groups based on their resemblance. Principal components analysis (PCA) is one of the important and common multivariate methods. Various trails have used the correlation $\mathrm{CA}$ and PCA to analyze the qualities of sugar beet genotypes. Jia et al. 2015 conducted comprehensive quality evaluations on some sugar beet genotypes from different producing zones by using the techniques of PCA and CA for the contents of several components. 


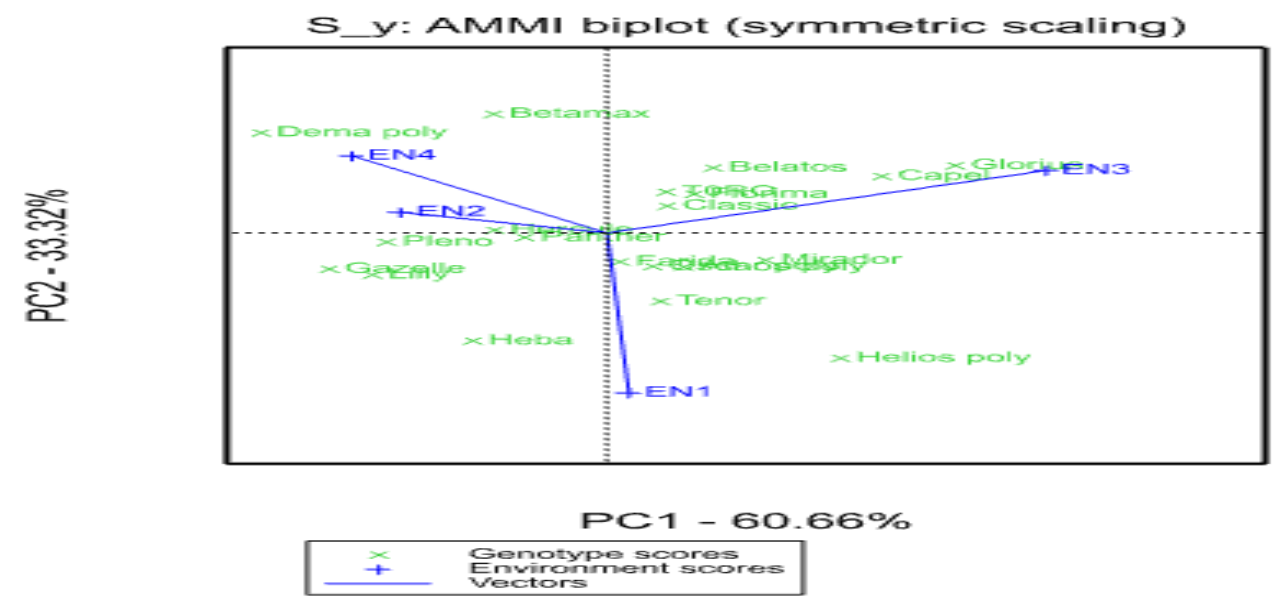

Figure 1. The AMMI biplot showing relationship between genotypes and mega environments for sugar yield.

R_y: AMMI biplot (symmetric scaling)

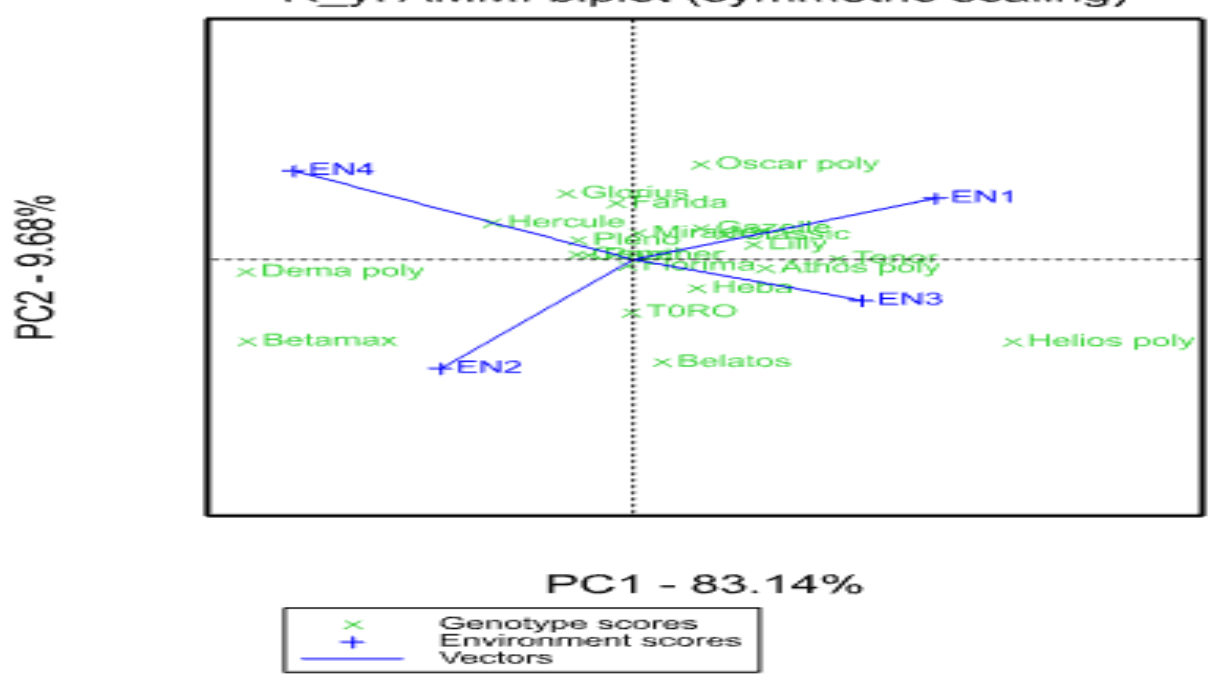




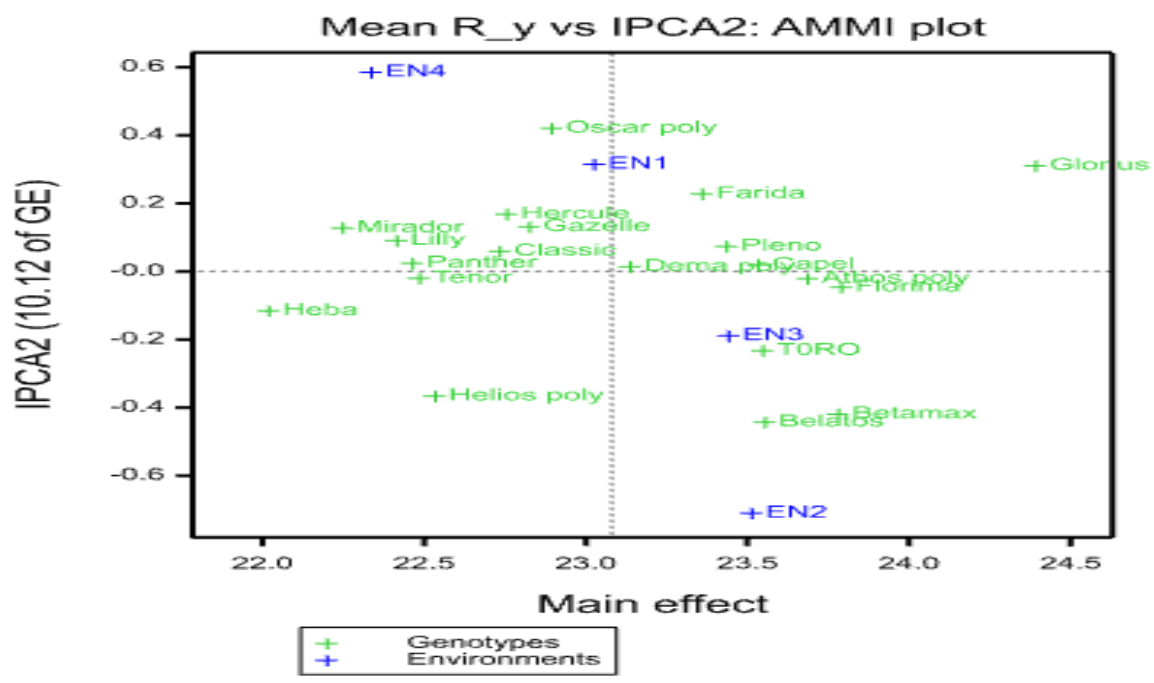

Figure 2. The AMMI biplot showing relationship between genotypes and mega environments for root yield.

\section{Cluster Analysis (CA)}

Cluster analysis is a tool for categorizing objects into groups. The cluster analysis was used as an efficient procedure to emerge the structural relationships among studied varieties and offers a hierarchical classification of them.

\section{Genetic Diversity}

Twenty genotypes of sugar beet were grouped into five clusters based on D2 -statistics in such a way that genotypes within a cluster had a low D2 values than those of in-between the traits. The composition of clusters has been depicted in (Table 6). The distribution pattern of genotypes displayed that cluster I I had maximum number of genotypes (6) followed by cluster VI (5) genotypes and then by other three clusters (3) genotypes each cluster. The inter-cluster distance different from 8.64 to
2.78. The highest inter-cluster distance was noticed in the cluster V and III (8.64). Conversely, minimum distance was observed in cluster VI and II (2.78); indicating close relationship between these clusters would not provide good results.

The existence of genetic divergence among the twenty genotypes sugar beet was examined by employing Mahalanobis's D2 statistic. The clustering pattern of these genotypes on the basis of D2 analysis has been offered in (Table $6)$. The genotypes were clustered into five distinct clusters. In the present study, based on Euclidean distance, the studied varieties were estimated with root and sugar yield and its related traits and were discriminated as shown in Figure 1. Mean values of root and sugar yield and its related traits under each tested cluster are offered in Table 7. 
Mehareb et al., SVU-International Journal of Agricultural Sciences, 3 (1): 96-111, 2021

Table 6: Distances Between Cluster Centroids

\begin{tabular}{|c|c|c|c|c|c|}
\hline & Cluster1 & Cluster2 & Cluster3 & Cluster4 & Cluster5 \\
\hline Cluster1 & & 4.4511 & 3.8064 & 3.89874 & 6.8007 \\
\hline Cluster2 & & & 6.22753 & 2.77513 & 3.60224 \\
\hline Cluster3 & & & & 4.34817 & 8.63682 \\
\hline Cluster4 & & & & & 4.38073 \\
\hline
\end{tabular}

Cluster analysis placed varieties into five groups (Figure 3) in dendrogram (A, B, C, D and $\mathrm{E})$. The maximum number of genotypes in the dendrogram (group B), consisted of six genotypes; Farida, Toro, Capel, Florima, Betamax and Glorius

It could be seen from Table 7 and Figure 3 , that the cluster analysis discriminated the targeted varieties into two major which could be named; Cluster A and B. Though, the first chief cluster divided into two sub clusters namely, cluster I cluster II. The $2^{\text {nd }}$ main cluster B contained three sub clusters (III, IV and V).

Considering the $1^{\text {st }}$ sub cluster (cluster I), it comprised of three genotypes; Athos poly, Pleno and Belatos. These genotypes were characterized by the high values of root weight, length, diameter and total weight. However, It is clear that the $2^{\text {nd }}$ sub cluster (cluster II) included six genotypes (Farida, Toro, Capel, Florima, Betamax and Glorius), that had the highest values of root weight, length, diameter and total weight Where it attained $106.95 \%, 105.68 \%, 122.76 \%$ and $108.33 \%$ in the combined compared with cluster V (Lilly, Heba, Mirador) respectively. The cluster number 5 (cluster V) included the genotypes that gave the minimum value of most traits.

Finally, traits of yield ( root and sugar), it was found that cluster II recorded the highest root and sugar yield, which led to increase of $106.66 \%$ and $112.91 \%$ higher than that compared with cluster $\mathrm{V}$.

In the light of prior results that showed the presence of considerable genetic diversity among the studied varieties, it provided a good chance to realize sufficient scope for genotypic improvement of sugar beet through the evaluation of sugar beet genotypes under different environmental conditions among varieties taken from divergent clusters to assemble desirable characters with higher heterotic potential. ((Xiao-Hang $\mathrm{Hu}$ et al 2019, Bassoniy et al 2019). 


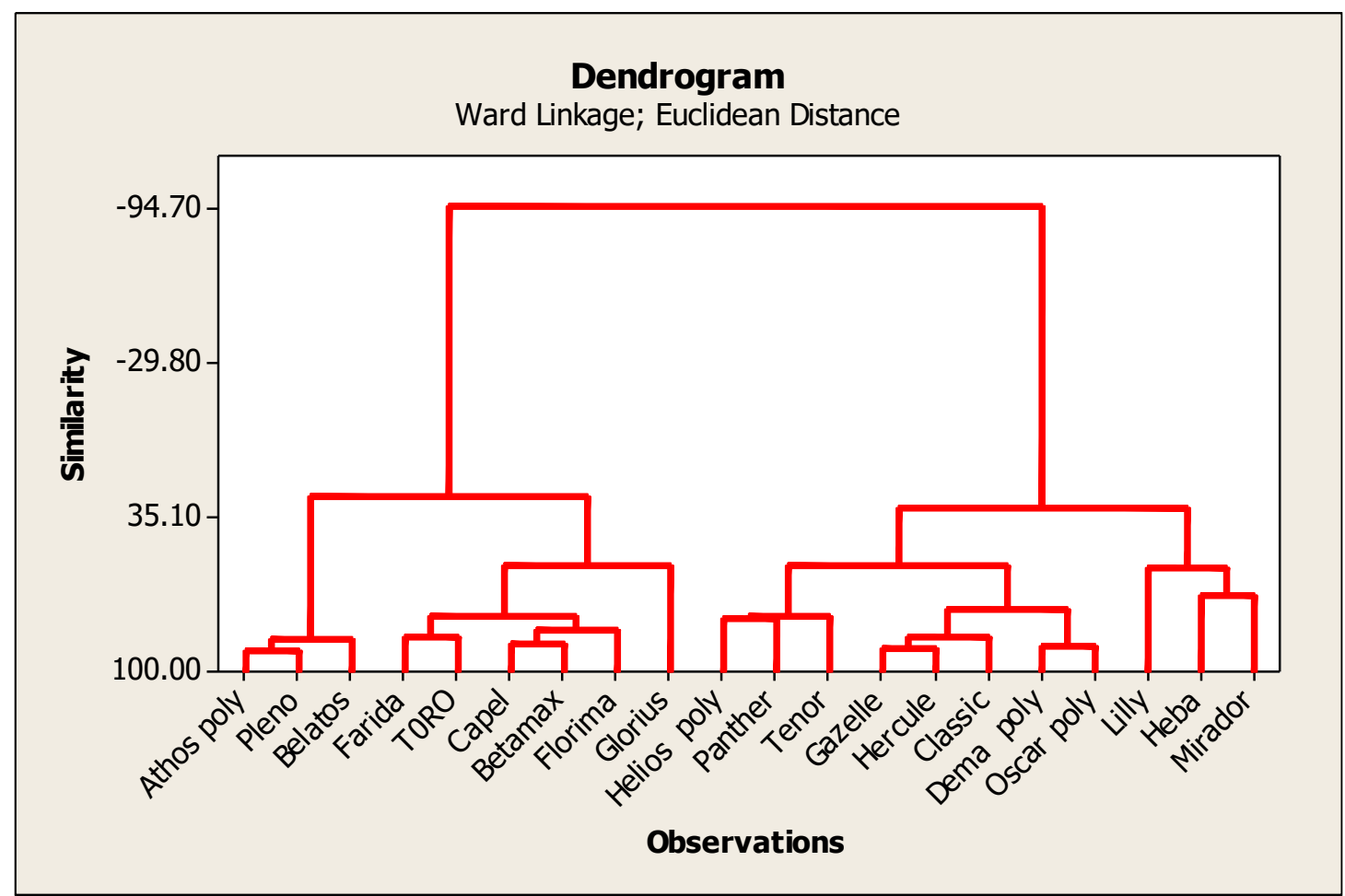

Figure 3. Dendrogram showing the distance among 20 sugar beet genotypes based on yield And its related attributes

Table. 7: Summary of cluster analysis showed the twenty sugar beet genotypes.

\begin{tabular}{lccccc}
\hline \multicolumn{1}{c}{ Groups } & Cluster I & Cluster II & Cluster III & Cluster IV & Cluster V \\
\hline Varieties/group & $\begin{array}{l}\text { Athos poly, } \\
\text { Pleno, Belatos }\end{array}$ & $\begin{array}{l}\text { Farida, TORO, } \\
\text { Capel, Florima, } \\
\text { Betamax, Glorius }\end{array}$ & $\begin{array}{l}\text { Helios poly, } \\
\text { Tenor, Panther }\end{array}$ & $\begin{array}{l}\text { Gazelle, Classic, } \\
\text { Dema poly, Oscar } \\
\text { poly, Hercule }\end{array}$ & $\begin{array}{l}\text { Lilly, Heba, } \\
\text { Mirador }\end{array}$ \\
\hline No. of varieties/group & 3 & 6 & 3 & 5 & 3 \\
\hline & \multicolumn{7}{c}{ Traits mean/group } & & 1.05 & 1.01 \\
Root weight/plant (kg) & 1.07 & 1.09 & 1.04 & 27.68 & 26.90 \\
Root length (cm) & 28.28 & 28.42 & 27.35 & 12.17 & 11.74 \\
Root diameter (cm) & 12.60 & 12.72 & 11.84 & 0.270 & 0.240 \\
Top weight/plant (kg) & 0.290 & 0.300 & 0.260 & 22.87 & 22.23 \\
Root yield/fed (ton) & 23.56 & 23.71 & 22.50 & 4.03 & 3.81 \\
Sugar yield/fed (ton) & 4.26 & 4.30 & 4.01 & 17.60 & 17.12 \\
Sucrose\% & 18.06 & 18.14 & 17.82 & 2.98 & 3.05 \\
Sugar lost in molasses & 3.07 & 2.93 & 3.06 & 14.62 & 14.06 \\
(SLM\%) & 15.00 & 15.21 & 14.76 & 82.99 & 82.05 \\
Sugar extraction \% & 82.98 & 83.72 & 82.78 & & 5 \\
Quality index\% & & & & & 3 \\
\hline
\end{tabular}


Table 8. Principal component analysis of measured characters in sugar beet genotypes in two locations and two seasons

\begin{tabular}{ccccccccc}
\hline \multicolumn{1}{c}{ Variable } & PC1 & PC2 & PC3 & PC4 & PC5 & PC6 & PC7 & PC8 \\
\hline Root Weight/plant (kg) & 0.30 & -0.08 & -0.11 & 0.01 & 0.09 & 0.39 & -0.24 & 0.27 \\
Root length (cm) & 0.29 & -0.13 & 0.01 & 0.18 & 0.16 & 0.15 & 0.65 & 0.57 \\
Root diameter(cm) & 0.29 & -0.18 & -0.17 & 0.03 & 0.18 & -0.06 & 0.53 & -0.68 \\
Top weight /plant (kg) & 0.29 & -0.15 & -0.09 & 0.11 & 0.09 & 0.68 & -0.29 & -0.27 \\
Root yield /fed (ton) & 0.29 & -0.16 & -0.15 & 0.12 & 0.25 & -0.38 & -0.26 & 0.08 \\
Sugar yield/fed (ton) & 0.29 & -0.19 & 0.09 & 0.05 & -0.06 & -0.25 & -0.16 & 0.00 \\
K content & -0.14 & -0.49 & 0.15 & -0.54 & 0.19 & 0.04 & 0.01 & 0.08 \\
Na content & -0.21 & -0.29 & -0.26 & 0.64 & -0.42 & -0.01 & 0.01 & 0.01 \\
Alpha-amino N content & -0.16 & -0.02 & 0.73 & 0.47 & 0.43 & 0.04 & -0.05 & -0.10 \\
Sucrose\% & 0.26 & -0.19 & 0.37 & -0.07 & -0.41 & -0.06 & -0.01 & -0.08 \\
SLM\% & -0.21 & -0.46 & 0.04 & 0.02 & -0.04 & 0.03 & 0.00 & 0.04 \\
Sugar extraction \% & 0.28 & -0.09 & 0.33 & -0.07 & -0.37 & -0.06 & -0.01 & -0.08 \\
Purity\% & 0.29 & 0.17 & 0.19 & -0.04 & -0.29 & 0.03 & 0.05 & 0.14 \\
Plot weight & 0.29 & -0.16 & -0.15 & 0.12 & 0.25 & -0.38 & -0.26 & 0.08 \\
Eigenvalue & 10.42 & 2.48 & 1.12 & 0.520 & 0.217 & 0.120 & 0.079 & 0.029 \\
Proportion & 69.50 & 16.60 & 7.4 & 3.5 & 1.4 & 0.8 & 0.5 & 0.2 \\
Cumulative & 69.50 & 86.09 & 93.5 & 96.9 & 98.4 & 99.2 & 99.7 & 99.9 \\
\hline
\end{tabular}

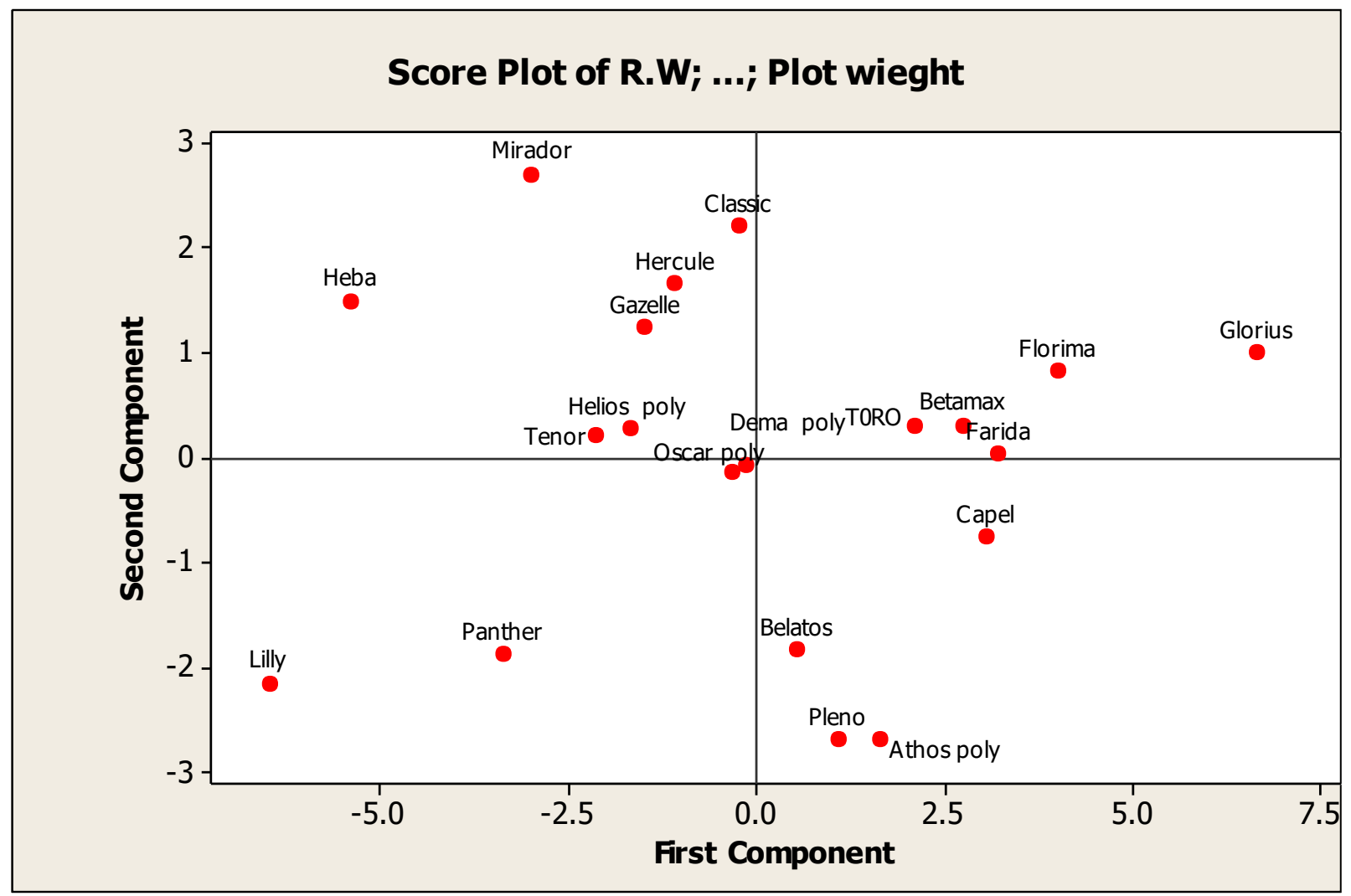

Figure 4. Principal component analysis of measured traits in the 20 sugar beet genotypes. 


\section{B- Principal Component Analysis (PCA)}

To show the genetic variability between sugar beet varieties, PCA of standardized data was applied to show characters relationships, and its application in variety traits and contrast (Table 8). As various characters use different units, the data standardization is essential to remove the units. Principal components, PC1 and PC2 were scaled so that values are symmetrically distributed between the variety scores and character scores. A variety by character biplot is constructed by plotting the PC1 scores contrary to the PC2 scores for each genotype (20 genotypes) and each trait (15 traits). The genotype by character biplot effectively exposes the interrelationships among sugar beet characters (Fig. 4). It also offers a tool for visual contrast among genotypes based on several characters. The results of the genotype by trait biplot, explained $69.5 \%$ of the total phenotypic variation expressed, and are a good approximation of the total variation of the standardization data.

Characters accounting for the most of difference expressed in the PCA1 were root weight and root diameter (Table 8). The second PC accounted for $27.03 \%$ of the variation with root weight and root length as the main traits in this component.

Numerous indexes are available for evaluating the sugar beet genotypes traits, and the variances in quality among genotypes were attributed to a lot of interacting factors Xiao et al 2017. In general, variable indicators selected using the PCA technique based on dissimilar quality traits could not only accelerate the evaluations manner but also allow scientific screening of high-quality varieties and avoiding of the waste of resources. For that reason, the PCA technique has been widely applied in several crops Dray and Josse 2016, Li et al 2017 and Abo elenen et al 2019

The genotypes Mirador, Lilly and Glorius were located at extreme positions from the origin in the PCA biplot while the genotype Oscar poly and Farida were concentrated around the origin on PC2. The results of the PCA analysis were offered in groups of genotypes to infer relationships among genotypes (Figure 4). PCA is an important breeding tool generally used by breeders to recognize characters that could be used to discriminate crop varieties. (Johnson, 2012 and Abo elenen et al 2019).

Table 8 show principal component analysis (PCA) that out of the eight components, the first four components described the majority of the total difference and contributed $96.9 \%$ of the total variation among the genotypes. PCA goals to resolve the total dissimilarity of a set of characters into linear, independent composite characters, which successively maximize variability in the data (Johnson, 2012). Considering a minimum threshold eigenvalue of one, the four principal components (PCs) accounted for a cumulative of about $96.9 \%$ of the whole phenotypic diversity observed among the genotypes. These results are in harmony with (Abraha et al., 2015; Chikuta et al., 2015). Abraha et al. (2015), Massaoudou et al. 2018 and Abo elenen et al 2019) that stated four principal components with eigenvalues superior than one, which explained $>75 \%$ of the total difference for the characters.

It could be concluded from the result the PCA and CA methods were combined to establish a model to evaluate the qualities according to the comprehensive evaluation indicators and 
information from this study might provide a feasible approach for the comprehensive quality evaluation of sugar beet genetic cultivars in China (Xiao-Hang Hu et al 2019)

\section{Conclusion}

In the study, we used three methods: AMMI method to evaluation the $\mathrm{G} \times \mathrm{E}$ interaction in varieties of stability and adaptability through dissimilar environments. cluster method classify the interrelationships among the studied varieties, Principal component analysis method was used to describe the relationship between the studied traits. Final results showed that the elite varieties, Glorius, Florima, Capel, Belatos, Classic and Toro recorded the highest sugar yield and stable performance at ElDakahlia station.

\section{References}

Abo Elenen, F.F.M., Helmy, S.A.M., Mehareb E.M., Bassiony, N.A.M. (2019) 'Genetic diversity and principal component analysis for agronomic and technological characterization of sweet sorghum germplasm under Egyptian conditions' Direct Res. J. Agric. Food Sci., 7 (12), pp. 375-384.

Aghayee-Sarbarzeh M., Safari, H., Rostaei, M., Nadermahmoodi, K., Pour Siabidi, M.M.A., Hesami, K. Solaimani, M.M., Mohammadi, R. (2007) 'Study of general and specific adaptation in dry land advance wheat (Triticum aestivum L.) lines using GE biplot based on AMMI model' Pajouhesh and sazandegi. 77: pp.41-48. (in Persian)
Akura, M., Kaya, Y., Taner, S. (2005) 'Genotype-environment interaction and phenotypic stability analysis for grain yield of durum wheat in Central Anatolian Region' Turkish J. Agric. For., 29: pp. 369-375.

Al-Naggar, A.M.M., R .M. Abd El-Salam and Walaa Yaseen Saad Yaseen (2018) 'Yield Adaptability and Stability of Grain Sorghum Genotypes across Different Environments in Egypt using AMMI and GGE-biplot Models' Annual Research \& Review in Biology 23(3): pp.1-16.

Annual Report of Egyptian Sugar Crops Council (2019) 'Sugar crops and sugar production in Egypt in 2017/2018 growing and Juice 2019 season'.

Baloch, A. (2017) 'Genetic diversity analysis in commercial sugarcane (Saccharum officinarum L.) genotypes' Pak J Biotechnol; 14(2). pp.167-71.

Bassiony, Noran A. Eman, M., Abdel Fatah, M., Khadijah, I. El-Gabry M., Mehareb, E.M. (2020) 'Yield performance and AMMI biplot analysis of some sugar beet varieties under olive mill waste treatments at multi environmental conditions', Direct Res. J. Agric. Food Sci.Vol.8 (2),pp. 48-61.

Crossa, J. (1990). "'Statistical analyses of multilocation trials' Advances in Agronomy. (44).pp. 55-85.

Dray, S., Josse, J. (2016) 'Principal component analysis with missing values: a comparative survey of methods' Plant Ecology, 216(5): pp.1-11. 
Ebdon, J.S. and H.G. Gauch, (2002) 'Additive mean effect and multiplicative interaction analaysis of national turfgrass performance trials' 1 . Interpretation of genotype $\times$ environmental interaction. Crop Sci., (42) ,pp.489-496.

Ebrahimian, H.R., Sadeghian, S.Y. Jahadakbar, M.R., Abasi Z. (2008) 'Study of adaptability and stability of sugar beet monogerm cultivars in different locations of IRAN' Journal of Sugar Beet. 24(2), pp. 1-13.

Farshadfar M., F. Moradi, A. Mohebi, and H. Safari (2010) 'Investigation of yield stability of 18 agropyron elongatum genotypes in stress and non-stress environments, using AMMI model' Iranian J. of Rang lands and Forests Plant Breeding and Genetic Research. 18(1),pp.45-54.

Gabriel, K.R. (1971) 'The biplot graphic display of matrices with application to principal component analysis' Biometrika. (58), pp. 453-467.

Gauch, H.G., Zobel, R.W. (1996) 'AMMI analysis of yield trials. Pages 1-40 in M. S. Kang and H. G. Gauch, eds. Genotype by environment interaction' CRC Press, Boca Raton, FL.

Ghareeb, Zeinab E.1; Hoda E.A. Ibrahim1; S.R.E. Elsheikh2 and S.M.I. Bachoash2 (2014) 'Genotype $\times$ environment Interaction for characteristics of some sugar beet genotypes' J. Plant Production, Mansoura Univ., Vol. 5 (5), pp. $853-867$

Hu, X.H., Wu, Y.M., Wang, X.W. (2016) 'Principal component analysis and comprehensive evaluation of amino acid in different varieties of sugar beet' Chinese Agricultural Science Bulletin, 32(27), pp. 69--75.

Jia, X.F., Zhu, S.M., Wang, Q., Long, W., Zhang, X.L. (2015) 'Principal component analysis and cluster analysis of the elements in sugar beet roots of different geographical origins in Xinjiang' Modern Food Science and Technology, (7), pp. 302-308.

Johnson DE (2012) 'Applied Multivariate Methods for Data Analysis' New York: Duxbury Press.

Keshavarz, S., Mesbah, M., Ranji, Z., Amiri, R. (2001) 'Study on stability parameters for determining the adaptation of sugar beet commercial varieties in different areas of ' IRAN J. of Sugar Beet. 17(1), pp. 15-36.

Li, W., Gao, H. Y., Chen, H. J., Wu, W.J., Fang, X.J. (2017) "Evaluation of comprehensive quality of different varieties of bayberry based on principal components' Analysis Journal of Chinese Institute of Food Science and Technology, 17(6)

Mundaragi, A., Thangadurai D, Bhat S, Sangeetha, J. (2017) 'Proximate analysis and mineral composition of potential minor fruits of Western Ghats of India' Scientific Papers Series A - Agronomy. (60), pp. 340-6.

Ngeve JM, Bouwkamp JC.

"Comparison of statistical methods to asses yields stability in sweet potato' Journal of American Society 
Horticultural Sciences; (118), pp. 304310.

Ranji Z., Mesbah, M. Amiri, R. Vahedi, S. (2005) "Study on the efficiency of AMMI method and pattern analysis for determination of stability in sugar beet varieties' Iranian Journal of crop sciences. 7(1), pp. 1-21.

Sabaghnia, N., Mohammadi, M. Karimizadeh, R. (2012) Grouping lentil genotypes by cluster methods related to linear regression model and genotype $x$ environment interaction variance' $Y y u$. $J$. Agric. Sci. (22), pp. 134-145.
Ward, J.J.H. (1963) Hierarchical grouping to optimize an objective function' Journal of the American Statistical Association, (58), pp. 236-244.

Xiao, Y., Juan, D.U., Yang, X.M., Pu, X.Y., Zeng, Y.W., Yang, T., Yang, J.Z., Yang, S.M., Chen, Z.Y. (2017) Analysis of functional ingredients in barley grains from different regions between Southwest China and ICARDA' Southwest China Journal of Agricultural Sciences, (30), pp. 8. 